\title{
Exploring city propensity for the market success of micro-electric vehicles
}

\author{
Ilona Loustric and Melinda Matyas
}

\begin{abstract}
As a subset of increasing EV growth and micro-mobility technology trends, micro-electric vehicles (micro-EVs) have the potential to address many transport system issues. Little research quantifies micro-EV potential, increasing investment risks. This paper builds an index to explore city propensity for micro-EV market success by incorporating differentiation, implementation, commercialisation, consumer and manufacturer requirements, and economic stability and viability aspects. The results highlight that micro-EV market success could most likely be influenced by the lock-in of the city's transport system. Despite inherent difficulties due to lock-in, our index suggests that there could be windows of opportunity for micro-EVs to be successful. Although both cities show a propensity for market success, Shanghai scores higher than London, highlighting that these opportunities may exist particularly in developing countries as they experience less lock-in and have more consumer incentives. Implementing micro-EVs in cities with higher propensity could have the domino effect of motivating change in other locations.
\end{abstract}

Keywords: Micro-electric vehicles, Innovation market success, City propensity, Lock-in, Transport

\section{Introduction}

The transition from the 19th to the twentieth century saw the global technological development of transport, especially in land transport [19]. Particularly of note is the explosion of personal mobility which has brought with it many positive consequences related to convenience, speed, comfort and freedom, as well as wider social and economic advantages. Despite these benefits, global transport systems are now increasingly threatening both the quality of life of individuals and the wider environment [13]. The expansion of a large car-based transport system has given rise to many persistent issues, such as congestion, accidents, noise and air pollution, social exclusion, land fragmentation, oil dependency and energy security concerns [20]. Experts suggest, that increasing pressures of population growth and climate change might be finally causing cracks to appear that are creating 'windows of opportunity' changes towards sustainability [45]. As such, transitions within the transport

\footnotetext{
* Correspondence: Melinda.matyas@ucl.ac.uk

MaaSLab, Energy Institute, University College London, 14 Upper Woburn Place, London WC1H ONN, UK
}

\section{Springer Open}

(c) The Author(s). 2020 Open Access This article is licensed under a Creative Commons Attribution 4.0 International License, which permits use, sharing, adaptation, distribution and reproduction in any medium or format, as long as you give appropriate credit to the original author(s) and the source, provide a link to the Creative Commons licence, and indicate if changes were made. The images or other third party material in this article are included in the article's Creative Commons licence, unless indicated otherwise in a credit line to the material. If material is not included in the article's Creative Commons licence and your intended use is not permitted by statutory regulation or exceeds the permitted use, you will need to obtain permission directly from the copyright holder. To view a copy of this licence, visit http://creativecommons.org/licenses/by/4.0/. systems whilst simultaneously attempting to tackle the drawbacks in order to take advantage of these 'cracks'. This transformation must integrate fundamental changes in mobility behaviour, spatial planning, traffic management and wider system infrastructure [20].

Electric vehicles (EVs), offer technologies that many consider fundamental in creating a sustainable future [4]. Another area of important development is micromobility - technologies that are tailored towards smallscale personalised use including e-bikes, scooters, hoverboards and micro electric vehicles (micro-EVs). Of these technologies, micro-EVs have become particularly interesting when considering the above-mentioned challenges of the transport sector. Micro-EVs are miniature electric cars that can carry one or two passengers. They are essentially a synthesised technology resulting from the adaptation of EVs to the micro-mobility context, which could have the potential to solve many of our transport issues [51]. Their advantages include both those of 'traditional' EVs and those of micro-mobility technologies, whilst simultaneously mitigating other additional transport problems, such as social exclusion. Thus, micro- 
EVs could contribute to solving some of the problems that the current transport system faces, although there still remains uncertainty as to where they are more likely to succeed, and what factors determine this.

The purpose of this paper is to explore the potential for market success of micro-EVs in global cities. This research will measure 'city propensity for market success' via the construction of a quantitative interdisciplinary index. Considering the multiple facets required to maximise micro-EV market success in a city provides insight into where this technology could potentially be first implemented, and explores the possibility of minimising company risk and innovation failure. London and Shanghai are two major global cities that micro-EV companies are hoping to target. They will therefore be utilised as case study cities to allow for initial exploration of the accuracy and sensitivity of the index.

The remainder of the paper is structured as follows. Section 2 will discuss the current transport system, particularly considering inherent difficulties caused by 'path dependency' and 'lock-in' phenomena. It will then provide some background on the two case study cities of London and Shanghai. This will be followed by a discussion on the current context of EVs and micro-mobility technologies, two innovations which are currently succeeding despite these phenomena, and which can also be considered the 'parent' technologies of the micro-EV. Building on the market successes of these technologies within current transport systems will thus enable us to identify possibilities for micro-EVs to fit within the wider transport narrative. Subsequently, Section 3 will explain the methodology for index construction, as well as the choice of case studies. Section 4 presents the results. Section 5 outlines possible implications of these results and Section 6 concludes by summarising the key findings of the index, highlighting study limitations and addressing potential future steps.

\section{Background}

\subsection{Characteristics of the current transport system}

Despite numerous attempts to integrate advances in the transport sector, the wider regime has predominantly resisted more radical innovations [35]. Indeed, the current transport system is characterised by "lock-in" and "path dependency" phenomena, which must be explained in order to understand the difficulties that innovations face when attempting to be achieve market success.

Path dependency is a self-reinforcing socio-technical process whereby each step along a given path increases the likelihood of continued steps in that direction, i.e., specific technologies and developmental pathways arise due to positive feedback loops or increasing returns to the adoption of specific innovations [15]. These positive feedback loops ultimately decrease the costs of the chosen technology and create additional benefits for consumers (ibid). Once a certain threshold is reached, the cost of reversing or changing the path's course becomes prohibitively high, and we say that the system is experiencing 'lock-in'. Indeed, this means that the various aspects of the overall system, including the material, organisational and conceptual dimensions, are all interlinked and interdependent, and a stable incumbent regime has been created whereby it is very difficult to displace existing technologies with new ones (ibid). The established technologies thus have a distinct advantage over new entrants, not because they are better technologies, but because they are more diffused and their adoption and usage is more widespread.

Currently, society is facing its biggest lock-in phenomenon, known as carbon lock-in, due to the world-wide dependency on fossil fuels as the dominant power source for all major sectors, including transport [28]. Modern, centralised automobility systems are technically complex and demanding, and are the product of many years of improvements of the various technological, socio-economic and political dimensions of the system [15]. Indeed, the historical development of ICEVs has repeatedly propagated positive feedback loops related to wealth creation and improvements in global accessibility, cementing ICEV stability within road transport. In particular, this has resulted from the need to have an inexpensive and reliable energy source as the central component to the system beginning from the period of industrialisation. Globally, this dominant energy source has been fossil fuels, and it continues to support high levels of travel consumption, particularly in most developed countries of the world [45].

Crucially, carbon lock-in can be subdivided into three major types which are all interlinked (ibid):

(a) Lock-in of the technologies and infrastructure which directly or indirectly emit $\mathrm{CO}_{2}$

(b) Lock-in of governance, institutions, and decisionmaking entities that affect energy-related production and consumption

(c) Lock-in of behaviours, habits and norms associated with demand of energy-related goods and services

Once a technology that uses carbon intensive fuel is selected, such as the ICEV, the gradual processes of lock-in lead those technologies which were not chosen to become less available, attractive and costlier. Those that were chosen gain the advantage of incumbency, inertia and support from the key economic, political and social groups that benefit from them [45]. Thus, systems which experience 'lock-in' have increased risks of innovation failure, as they make the costs and 
performance of all new technologies (both incremental and radical) more uncertain relative to the alreadyestablished system [28]. Yet electric lighting has displaced gas, and automobiles have replaced horses and carriages. Indeed, an innovation should be accepted if associated benefits outweigh the costs and if it gives rise to positive change [10]. So how can micro-EVs succeed in the face of lock-in?

\subsection{Background on case study cities: London and Shanghai}

\subsubsection{London}

Like many other cities, London's transport system is facing increasing pressures due to a rapidly growing population. At peak times, public transport operates at near maximum capacity, and for commuters, traffic congestion often results in hours of idling and stand-still traffic, impacting both individuals and the surrounding environment [47]. With predictions of ever-increasing population and urban growth, considerable investment will be needed for the system to sustainably accommodate the city's evolving needs (ibid).

Transport for London [49] has already begun to address these issues with expenditure plans that anticipate future transport requirements over the next few years, including schemes such as the Crossrail and the Tube Upgrade Programme. Mayor of London [30] has stated that "incorporating the environmental impacts of different transport systems in decision-making will become increasingly important", as the current system accounts for over $20 \%$ of $\mathrm{CO}_{2}$ emissions and over $50-60 \%$ of other major air pollutants within London. In fact, if transport emission levels per capita are not reduced, the UK will miss its 2050 climate change reduction targets. Responding to these challenges, the British government put forward a series of commitments that aim to convert the city's automobile fleet to be "as clean as possible, as fast as possible" (ibid). One such commitment involves targeting EV uptake by developing an effective charging infrastructure, accelerated by the $£ 400$ million Charging Infrastructure Investment Fund. Projects such as this aim to increase the convenience of owning an $\mathrm{EV}$, subsequently increasing consumer demand and simultaneously encouraging vehicle manufacturers to turn towards electrifying their vehicle models (ibid).

These initiatives are further complemented by the Administration's new emissions-based parking system within the Square Mile zone, which places greater charges on high-polluting vehicles, and rewards drivers of low-emissions vehicles, including EVs, with lower tariffs [12].

Moreover, the UK government is hoping to anticipate future technological uncertainty by implementing a flexible regulatory framework that targets 'new areas' of development, particularly by considering micro-mobility vehicles for the movement of people and goods (ibid). Establishing this framework will enable future implementation and wider use of these technologies without the need to change road legislation each time.

As it stands, London clearly recognises the benefits of EVs, promoting their use and augmenting their infrastructural capacity, and anticipates future micro-mobility growth. However, the evidence for the status of microEV technologies in the city is still lacking, making London the ideal case study for analysis of the potential success of micro-EVs.

\subsubsection{Shanghai}

Shanghai began as a small fishing village, but the construction of the port increased trade, rapidly multiplying the population of the area. To accommodate Shanghai's major growth, the city's roads were increased by over $40 \%$ [9]. The number of privately-owned cars jumped to over one million by 2000 , and forecasts predicted that by 2020, Shanghai will have a vehicle fleet of over 2.5 million private cars, with daily vehicle trips doubling to over 7 million [42]. This development will have costly implications for the wider environment and society.

Firstly, Shanghai's car growth has resulted in a substantial increase in nationwide $\mathrm{CO}_{2}$ emissions. For China, where pollution is already costing $£ 1.5$ million in annual external costs [39], finding a sustainable transportation solution is of high priority. Furthermore, the country is already facing conflict between the growth in automotive ownership and issues related to national energy security [16]. Yet in 2009, the Chinese vehicle market overtook the US' to become the largest in the world (ibid). Recently, the government attempted to tackle these issues by promoting behavioural change initiatives; for example, supporting the popular taxi company Didi, to increase orders to rates of 5.5 million per day, helped to reduce overall daily emissions by 40 metric metres by decreasing the total number of cars in the city [52]. However, proportionally to the population size, this has not reduced car ownership enough.

China then turned towards the green pathway; expanding the EV market became a promising national development strategy, one which would enable China to solve sustainable transportation issues whilst simultaneously placing it at the forefront of the global automotive industry (ibid). Currently, the development of EVbased companies and the active promotion of their technology is expanding. Both central and local governments have also increased EV subsidies [33]. This has boosted internal sales, with growth rates surpassing previous estimates. Indeed, the adoption of EVs in Shanghai ranks amongst the most promising of the world (ibid). This 
electrical revolution includes the majority of the city's fleet; buses, public service vehicles and taxis have all been replaced by EV models. Private ownership is also higher than in many other cities, and Shanghai boasts the world's largest EV car-sharing program, with over 30,000 vehicles in operation [14]. Furthermore, China has become the world's largest micro-mobility market (Yang, Goldmann \& Lagercrantz, 2018). In Shanghai there are over 10 million shared mobility customers and 1.5 million shared bikes and the government is increasingly considering these small-scale technologies as important future urban solutions [48].

Despite pushing the EV and micro-mobility agendas, there is again little literature which outlines the current status of micro-EVs within the city. Similarly to London, this makes Shanghai an optimal candidate to explore the potential for micro-EVs success.

\subsection{Micro-EVs}

To better understand the possibility of market success of micro-EVs, it is crucial to first outline and discuss current trends for its two 'parent' innovations within the transport system, EVs and micro-mobility, which are both succeeding despite the aforementioned phenomena.

EVs are currently four times more energy efficient than Internal Combustion Engine Vehicles (ICEVs) and represent an important technological option for decarbonisation in transport $[7,23]$. In addition to offering a solution to numerous challenges inherently linked to ICEVs [5], EVs also mitigate issues related to local air pollution, climate change, noise pollution, oil dependency and energy security concerns. EVs might be more environmentally-friendly, but critics point to the possibility that shifts towards this technology might increase car usage and ownership, therefore augmenting the severity of congestion and spatial problems [20]. Interestingly, EV models vary by size, with smaller vehicles utilising reduced batteries. These smaller batteries have many benefits: i) increased efficiency, i.e. higher fuel-tooutput ratios, ii) reduced costs, and iii) lesser ecoimpacts [3]. This direct relationship between model size and emissions supports an imperative to develop smaller-scale technologies within transport [23], warranting a transition towards technologies known collectively as micro-mobility.

Micro-mobility refers to any personal vehicle that can carry one or two passengers and which is generally powered by batteries, including bicycles, scooters, hoverboards and micro-EVs [50]. The benefits of micromobility are also linked to their decreased size, and they therefore tackle a variety of transport issues, such as parking and congestion. Micro-mobility technologies are environmentally-friendly solutions that remain socially inclusive and tackle issues such as the first and last mile problem owing partly to their small size and consumer personalisation. Estimates of the potential of micromobility technologies conclude that by 2028 , there will be a market worth over US $\$ 41$ billion (ibid). Furthermore, micro-mobility solutions are much less expensive when compared to all other transport options. Whilst the reduced size of micro-mobility technology comes with many benefits, the main consumer disadvantage is its limited power and consequent inability to travel longer distances compared to ICEVs [6]. However, current research and development into these technologies is increasingly aiming to close this gap. Indeed, one micro-mobility technology that maintains the possibility for travelling a comparatively far distance is the micro-EV.

Micro-EVs are a subset of both EVs and micromobility: an innovation that aims to tackle current and future urbanisation problems. The technology consists of a small electric car with one or two seats, which operates utilising a similar, yet smaller, battery system, when compared to its larger parent vehicle [38]. Micro-EVs also have a more compact size as the majority of them are built from carbon fibre with bio-composite bodies (ibid). Thus, they are smaller and lighter than their standard counterparts, and are described as ideal for city driving' [25]. Furthermore, their small size means that less resources are needed to build the battery and that the impact of end-of-life disposal is almost negligible (ibid). Moreover, the reduced size of micro-EVs limits their top speed, making them less dangerous than other road vehicles and exempting them from certain crashtesting requirements. In some countries, such as China, no license or insurance is required for operation, highlighting their ease of use and convenience [51].

Micro-EVs can be summarised as electric transport technologies that have the following characteristics [24]: (1) a small size to occupy minimum road and parking space, (2) high manoeuvrability, (3) minimum pollution, (4) ease of operation, and (5) low initial and running costs. This enables the technology to have the potential to tackle or minimise the same transport issues as both larger EVs and micro-mobility technologies combined, as well as possibly going further to mitigate other problems such as end-of-life disposal complications. Furthermore, predictions suggest that their suitability might even extend into societal norms: new generations prefer fit-for-purpose mobility solutions, and the micro-EV could align with these preferences [44]. Micro-EVs could also act as the missing affordable compromise between e-bikes and EVs; the price of a micro-EV remains far below that of other EV types and, despite being costlier on average than a bicycle, some model prices remain relatively competitive [51]. A summary of the benefits of micro-EVs can be found in Table 1 below. 
By 2026, analysts envisage that the micro-EV market could reach over $\$ 33$ billion [22]. Zion Market Research [54] states that the largest micro-EV markets are currently Europe and North America, but that micro-EVs could have the capacity to fill market gaps everywhere including in developing countries. In the foreseeable future, Asia Pacific is expected to emerge as the fastest growing regional segment for micro-EVs with China as the primary investor.

Due to their novelty, the exact positioning of the micro-EV within transport remains uncertain. It is hoped that as the technology develops, further iterations of the index might be tweaked to address their specific role more precisely.

\subsection{Composite indicators}

As mentioned, scarce literature explains the current micro-EV context, suggesting that the dissemination of this technology still remains relatively stagnant. In addition, few studies attempt to forecast their future global potential, despite experts highlighting micro-EVs as a technology with many benefits. There is a degree of risk involved in the promotion of innovations, with many promising novelties failing to succeed. This is principally due to inherent difficulties throughout the innovation process, particularly between the research output and technology success phases.

To reduce the risk of market failure, firms and governments must have a way of assessing the potential for market success of the innovation. When talking about this 'innovation market success', it is crucial to consider various dimensions: consumer and company requirements, diffusion, implementation, commercialisation and economic viability and stability [41]. These variables are known as wider framework conditions (WFCs) [2]. WFCs define and determine the flows of knowledge, people and resources, enable the necessary interactions and therefore shape the conditions for business'

Table 1 Summarised micro-EV benefits

\begin{tabular}{ll}
\hline Micro-EV Characteristics & Benefits \\
\hline Electric battery & Minimum pollution, \\
Lmall size & $\begin{array}{l}\text { Low running costs } \\
\text { Occupy minimum road and } \\
\text { parking space, } \\
\text { Less resources needed to build } \\
\text { the battery, } \\
\text { Smaller end-of-life disposal impact, } \\
\text { Fit-for-purpose solution }\end{array}$ \\
High manoeuvrability & Ease of operation, \\
Limited top speed & More suited to city driving \\
Driver's licenses/insurance not & Reduced danger when driving \\
needed in certain countries & Ease of use and convenience \\
\hline
\end{tabular}

knowledge transformation and exploitation. By considering the WFCs and their interactions, this research aims to go beyond disciplines such as Engineering, Planning, Economics and Psychology which prevail in transport studies [20], drawing additional insights from Business, Innovation, Political Science and Sociology. This underscores the broad scope of this study: it is difficult to pinpoint a universal algorithm for quantification of innovation market success, and there is no absolute list of relevant WFCs for under-researched technologies such as micro-EVs.

Composite indicators (CIs), or indexes, are commonlyused tools to quantify country or city performance in areas such as sustainable development, globalisation and innovation, as they enable the user to consider elusive issues in wide-ranging fields [31, 41].identify four key reasons which highlight the usefulness of such indexes:

1. They allow for the synthesis of large data masses

2. They show the current position in relation to desirable states

3. They highlight progress towards intended goals and objectives

4. They effectively communicate current status to stakeholders, showing the areas which have scored lower and demonstrating where decisions can be taken that lead towards the targets

CIs are also utilised to express the need to improve the sustainability of transport systems at both a global and local level as they can consider all three key pillars simultaneously: the economic, the environmental and the social. The combination of these uses thus makes the index an attractive tool for the purpose of this research, which will seek to construct a CI that can effectively explore the current propensity for market success of micro-EVs in cities around the globe. Existing research by Roumboutsos et al. [43] considers the complex relationships between actors, institutions, mechanisms and market conditions to examine how EVs may be successfully deployed in cities. The present study will draw from their methodology in its comparison of multiple facets of the innovation system for sustainable transport technologies, whilst highlighting the need for research to focus specifically on micro-EV technologies (ibid). In particular, it is hoped that the construction of this CI will provide an appropriate exploration of city propensity for micro-EV market success that could mainly be helpful for investors, but could also be relevant for other stakeholders in the micro-EV or transport sectors. Indeed, this is because the CI will hope to explore the relationship between city propensity for market success and the inherent lock-in of transport systems. 


\section{Methodology}

Previous studies attempting to predict the market success of transport innovations have customarily created a baseline that is consistent with historical transport trends [53]. However, it is important to recognise the degree of uncertainty associated with extrapolating current trends for future projections, which relies on the assumption that patterns will remain consistent moving forward (ibid). This research will circumvent this assumption by utilising a different methodology: the construction of a CI with which it is hoped that micro-EV potential can be ranked by city, and the development of this then tracked over time. The index will be constructed following the guidelines of the OECD Handbook for Composite Indicators [37]. It is important to consider that there are a variety of different CIs, and a variety of ways in which experts suggest they be constructed. The Handbook (ibid) is primarily concerned with those which compare and rank country performance in domains such as industrial competitiveness, sustainable development, globalisation and innovation. As the possible market success of micro-EVs relies primarily on these same principles, an adaptation of the Handbook's methodology (ibid), applied instead to city performance, seemed most suitable for the construction of the CI. In addition, the research will analyse various existing indices which quantify different aspects of innovation, market success, and transport. Appropriate models with comparable aims will seek to provide established, credible frameworks from which to base our own research. Although each index aims to quantify a slightly different concept, there are various subcategories that overlap under central themes. Quantification of some of the values for our proposed index will be developed from these existing indices (e.g. Domestic market scale), and this process will be outlined and justified in Data Selection. Finally, the index's reliability and accuracy will be tested using two case study cities: London and Shanghai. The evidence for the status of micro-EV technologies in both cities is still lacking, making them the ideal case studies for analysis of the potential market success of micro-EVs.

\subsection{Our index}

It is important to consider the degree of subjectivity in justifying the effectiveness of a $\mathrm{CI}$, particularly in relation to emerging policy areas such as sustainable development, as analysis is often based on 'fit-for-purpose' interpretations and peer acceptance (ibid). Transparency is imperative for subjectivity not to influence the overall credibility and clarity of the index. The proposed CI will be built following the steps presented in Fig. 1 to avoid data manipulation and misrepresentation.

\subsubsection{Theoretical framework}

This provides the core for the selection and combination of distinct indicators into one meaningful CI, and is generally constructed on a 'fit-for-purpose' basis, i.e. through the involvement of experts and stakeholders. This study utilises only secondary resources, specifically through the instruction of the OECD Handbook [37], in conjunction with the analysis of existing, peer-approved indexes, to build this 'fit-for-purpose' framework. The primary benefit of utilising secondary sources is that it enables the framework and data points to be rapidly updated and thus maximises the index's potential benefit for investors and other relevant stakeholders.

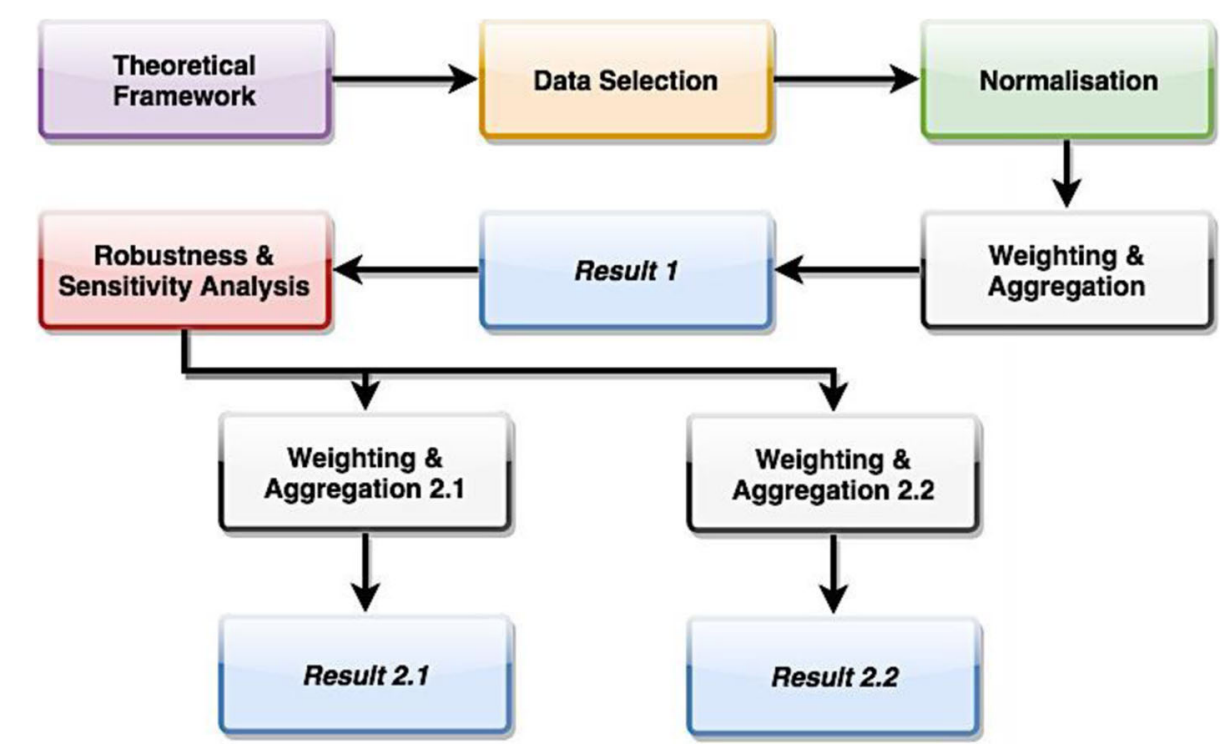

Fig. 1 Methodology steps (author's work) 
Firstly, we defined the concept and distinguished the underlying motivations: Our research aims to quantify the current propensity for market success of micro-EV technologies in cities.

The EEA [18] has highlighted 'traditional' EVs as a key sustainable technology, particularly due to their low carbon emissions, and as discussed in the Background, micro-EVs have even smaller eco-impacts than their larger counterparts. Combined with their novelty, microEVs can therefore be perceived as 'sustainable innovations'. Thus, the framework of our research will consider "sustainable innovations" - "processes where sustainability considerations (environmental, social, financial) are integrated into systems from idea generation through research and development and commercialisation." [8]. Alongside this, the creation of this index will be framed by considering wider aspects of $\mathrm{EV}$ and road transport which are deemed relevant to micro-EV technology, as per the review of the technology in the Background section. For all selected relevant variables, "success" will be measured based on the current real-world maximum for market, economic, legal and organisational variables in aspects of technology diffusion, wide-scale implementation, commercialisation, company and consumer requirements and wider economic frameworks [36].

\subsubsection{Data selection}

This step is crucial to maximise the accuracy of the index as it involves choosing the relevant variables that will be measured. According to Joumard \& Gudmundsson [27], the data selection should adhere to the following 10 criteria: validity, reliability, sensitivity, measurability, data availability, ethical concerns, transparency, interpretability, target relevance and actionability. Indexes from other disciplines exist which follow these criteria and are wellrecognised in their various fields of study. Three of these have provided our research with a useful basis for the creation of our new index:

1. The Global Innovation Index (GII) outlines necessary criteria for a city's best chance of innovation market success, providing insight into crucial aspects needed for effective diffusion, implementation and commercialisation [17].

2. The Global Cleantech Innovation Index (GCII) proposes necessary criteria for the market success of a cleantech innovation company, including aspects likely to encourage end-user uptake [46].

3. The Market Potential Index (MPI) provides necessary criteria to measure optimum market potential and economic stability [32].

To help focus the scope of our research, only the most pertinent categories were discussed from each index. The variables utilised in this study were then chosen based on this review of existing indexes, as well as on expert elicitation and the literature and background review, modifying the information to fit the micro-EV context. Combining the GII, GCII and MPI thus enables construction of a comprehensive index that measures innovation diffusion, implementation, commercialisation, consumer and manufacturer requirements and economic viability and stability, producing an overall analytical framework of 'city propensity for micro-EV market success'.

The second step of Data Selection entailed identifying suitable ways to measure each selected variable [37]. Following the literature review, composite measures were selected where possible for their peer-approved methodologies, and thus, eight of the 16 subcategories are composite measures which have been appropriated from existing indexes. The remaining eight subcategories were self-constructed using the Handbook's guidelines. This produced a final listing of subcategories and associated quantification methods (presented in Table 2).

\subsubsection{Imputation of missing data}

Where possible, our research quantifies variables using city-specific measures to enhance accuracy. However, this was not feasible for Domestic Market Scale and $R \mathcal{E} D$. In the cases were this data could not be obtained or calculated, country-specific measures were used as a viable 'closest possible data' alternative [37]. Categories such as Country Risk, Political Risk, and Rule of Law are subcategories that required country-specific measures. Savings from Electricity is assumed to remain consistent throughout the country.

\subsubsection{Normalisation}

This phase is key to render the different variables comparable. According to Luzzati \& Gucciardi [29], one of the most utilised normalisation methods for indexes is the min-max method. This linearly rescales the data by assigning 0 to the worst value and 1 to the best, giving the normalised result, denoted by $I_{c}^{q}$, as a value between 0 and 1 inclusive. The original data point is $x_{c}^{q}$ for any indicator $q$ and city $c$, and the $\max \left(x^{q}\right)$ and $\min \left(x^{q}\right)$ are the real-world maximum and minimum values respectively for the indicator $q$ across cities. This method enabled us to assign the maximum as our definition for 'success' within each subcategory. The process follows this equation:

$$
I_{c}^{q}=\frac{x_{c}^{q}-\min \left(x^{q}\right)}{\max \left(x^{q}\right)-\min \left(x^{q}\right)}
$$

Since only indicators with the same direction can be aggregated to the overall index (i.e. all positive contributions), any indicator $q$ for city $c$ having a negative 
Table 2 Final index categories (author's work)

\begin{tabular}{|c|c|c|}
\hline Category & Origin & Measurement Method \\
\hline Regulatory quality ${ }^{\mathrm{a}}$ & Gll & "Doing Business 2018" - city ranking \\
\hline Rule of Law ${ }^{a}$ & Gll & "GII" - country-assigned specific scores \\
\hline Education & Gll & Literacy rate of the city \\
\hline Research \& Development (R\&D) ${ }^{a}$ & Gll & "GII" - country-assigned specific scores \\
\hline EV charging ports & GIl/MPI (tweaked) & $\begin{array}{l}\text { Existing number of piles (both standard and } \\
\text { quick-charging) measured per capita of the city }\end{array}$ \\
\hline Savings from Gasoline over Electricity & GII/GCII (tweaked) & $\begin{array}{l}\text { Measured as the monetary savings }(£) \text { obtained } \\
\text { from travelling } 100 \mathrm{~km} \text { in an EV over a gasoline- } \\
\text { powered vehicle - country ranking }\end{array}$ \\
\hline Investment ${ }^{a}$ & GII/GCII & "Global Cities Investment Monitor 2018" - city ranking \\
\hline Domestic Market Scale ${ }^{a}$ & Gll & "GII" - country-assigned specific scores \\
\hline Price & GCll (tweaked) & Price of most sold EV type in $£$ - by city \\
\hline Green policies & GCII (tweaked) & Subsidies on EVs as \% of vehicle price \\
\hline Licenses & MPI (tweaked) & $\%$ of population who hold licenses - by city \\
\hline Ease of license availability & MPI (tweaked) & Registered license plates per capita - by city \\
\hline GDP growth rate & MPI & Yearly increase in GDP per capita of the city \\
\hline Business risk $^{\mathrm{a}}$ & MPI & "Lloyd's City Risk Index" - city ranking \\
\hline Country risk $^{a}$ & MPI & "Eulier Hermes Country Risk Ranking" - country ranking \\
\hline Political risk ${ }^{\mathrm{a}}$ & $\mathrm{MPI} / \mathrm{Gll}$ & "Political Risk Index" - country-assigned specific scores \\
\hline
\end{tabular}

${ }^{a}$ indicates a composite variable that has been quantified within a previous index

direction was transformed by assigning the best (worst) performer the value of the worst (best) one, i.e., utilising the following rule:

$$
\hat{x}_{c}^{q}=\max \left(x^{q}\right)+\min \left(x^{q}\right)-x_{c}^{q}
$$

It is important to note that this quantification of 'success' is a snapshot of each indicator at the given moment in time where the index is constructed. As such, it is recommended that the index be recalculated on a yearly basis in order to account for changes.

\subsubsection{Weighting and aggregation}

Weighting defines the relationship between the subcategory and the $\mathrm{CI}$ and must therefore align with the underlying theoretical framework and the data properties. The variables can be considered: (a) independently and equally - called Equal Weighting (EW); (b) as having differing levels of importance to the $\mathrm{CI}$, to be determined by either experts or the general public; (c) as part of overarching categories that group correlated indicators which describe similar dimensions [37]. This research utilises all three weighting methods. The EW methodology assigned each variable a weighting of 1 . The 2nd weighting methodology utilised a ranking system where the subcategories were ranked in perceived order of importance as per CI literature (ibid), then subdivided into groups of 4 and given equal weightings by group. The 'most direct consumer impact' subcategories were weighted the most (4/5), and each of the following 3 groups were weighted slightly less than the one directly preceding it (from $3 / 5$ to $1 / 5$ as per their ranked importance considering direct impact on consumer then company, then considering indirect impacts). The final weighting methodology grouped 'correlated' indicators into the overarching categories; each overarching category was assigned a weight of 1 to be equally divided amongst their respective subcategories. For more information on all three weightings please refer to the study conducted by Danieles, Rotaris \& Monte [11].

\subsubsection{Uncertainty and sensitivity analysis}

This entails testing the robustness of the index and the accuracy of results, and consists of re-analysing previous steps [37]. In this study, it was determined that the three weighting methods were necessary for maximum robustness. This multi-modelling approach provides us with alternative conceptual scenarios to better understand the relationship between the individual subcategories and their aggregated result and also avoids the oversimplification of the message to the reader (ibid).

\subsubsection{Visualisation of the results}

Generally, visualisation entails identifying the most suitable tools for communicating the results to the wider public. This research utilised JavaScript to transform the results into a simplified and accessible format (Fig. 2). 


\section{Results}

This research followed the 'philosophical' index construction approach formulated by Luzzati \& Gucciardi [29]: the CI was not used to obtain one single result, but rather, to generate three different rankings based on various weightings. Our normalised index therefore enables us to compare, both temporally and spatially, a city's propensity for micro-EV market success. The results will now be individually discussed followed by an analysis of overall extrapolated patterns.

\subsection{Result for equal weighting}

The overall score for the first weighting methodology for Shanghai was 0.587 and for London was 0.570 . Figure 2 shows the individual results of weighting each category equally for both cities, highlighting the better performer. This weighting methodology causes subcategory outliers of the index, such as those Price, to have a higher overall impact on results. Indeed, Allman [2] observes that variations in the strengths or weaknesses of WFCs will strongly affect innovation performance. However, in this first result, Shanghai and London scored similarly despite performing very differently throughout the WFCs. Both cities appear to have almost the same propensity for micro-EV uptake, which, given the differences in their separate subcategory results, is unlikely. Thus, the result from the equal weightings method is disadvantageous as it does not allow us to accurately assess the relationship between the index and individual subcategories.

\subsection{Result for ranking weighting}

The second set of results returns a relatively constant result for Shanghai, which scored 0.586, whilst a significant drop is observed for London, with a score of 0.474; Shanghai now leads by an $11 \%$ margin. The results were obtained from the ranking methodology which split the 16 categories into sets of four equally weighted categories, categorised from heaviest to lowest weighting below (Fig. 3).

The difference in the results becomes clear once the first eight categories are observed, as Shanghai surpasses London six times. The most significant difference is seen in the Price category. This is because the most popular micro-EV brand throughout Europe is the Microlino, the most expensive micro-EV on the market [38]. Utilising the min-max normalisation method means that London is thus assigned a score of 0 in this category. On the other hand, the Chinese market has micro-EV brands which can be obtained at almost 1/10th of the Microlino's price. These can be purchased through Alibaba, the Chinese website, and delivered directly to your doorstep [1]. It must be noted that we assume quality of different micro-EV brands to be relatively constant. The other major difference is observed in EV charging points. This was quantified as a per capita measure, and indicates that despite governmental efforts, the infrastructure is not significantly widespread relative to London's size. Conversely, many EV capitals in China, such as Shanghai, mandate a certain fraction of the city's parking spots be equipped with charging points [21], improving per capita charging capacity.

Clearly, Shanghai performs better in aspects that directly impact the two major stakeholders: consumers and

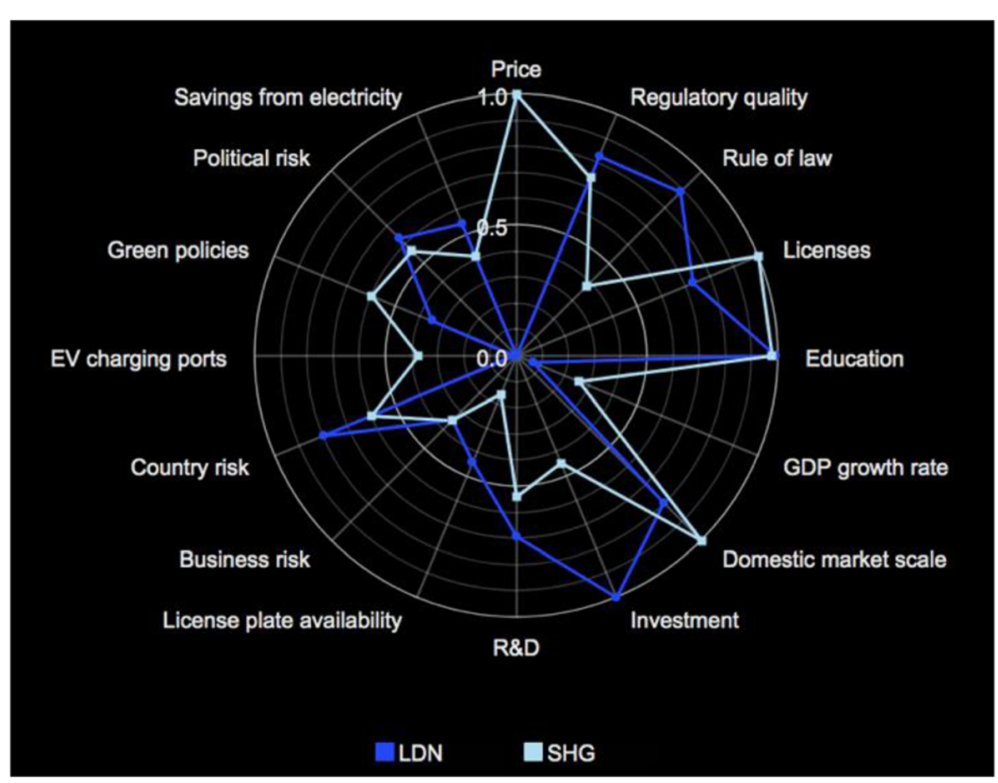

Fig. 2 Equal Weighting: all subcategories (author's work) 


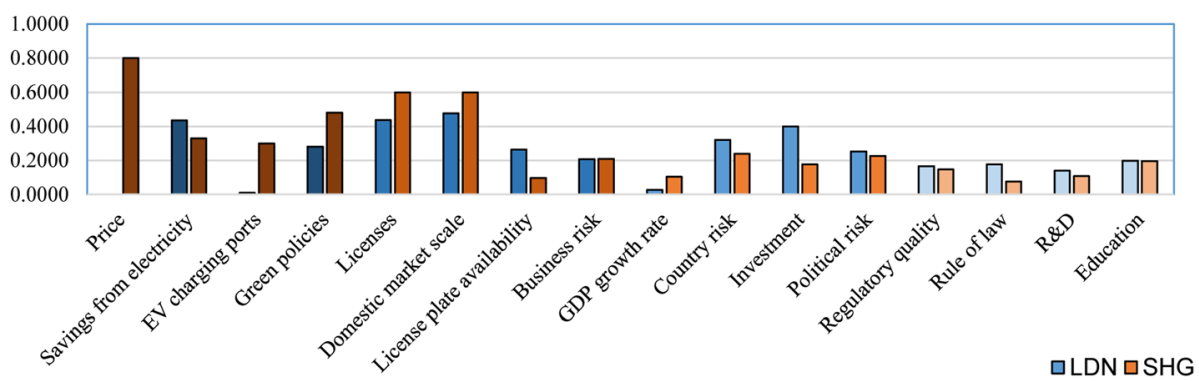

Fig. 3 Results 2.1 subcategories (author's work)

producers. Conversely, London's regulatory framework is more secure, the economic context is more stable and risks are lower. Despite this, these results demonstrate that a better city framework may be a more indirect consideration on the uptake of transport technologies, and therefore not be the most crucial characteristic for gauging micro-EV market success within cities.

\subsection{Results for overarching categories weighting}

The final weighting methodology again results in Shanghai having a higher score than London, with the cities obtaining 0.592 and 0.579 respectively. The third results are therefore similar to those observed for Equal Weighting despite different weighting approaches. This method groups the 16 subcategories underneath "Consumer Considerations", "Convenience", "People Development", "Country Framework" and "Risk". The "Convenience", "People Development" and "Country Framework" categories each have fewer subcategories than the other overarching classifications. Performance within those variables will therefore have a greater impact on the final result. As London performs well in those categories, its score increases to narrow the gap with Shanghai. Shanghai's result again remains similar to previous figures. All three methodologies point to the same results: Shanghai has, as it stands, a potentially higher propensity for micro-EV market success than London. In other words, micro-EV technologies are perhaps less likely to fail in Shanghai.

\section{Discussion}

As previously seen, current forecasts about the transport sector highlight increasing market growth for EVs, particularly if the technology is scaled down, and also predict that micro-mobility technologies are on the rise. As micro-EVs fit within these subsets, it follows that the technology will most likely experience rapid growth in the future. Yet, growth must start somewhere, and we have seen that many innovations often fail when attempting to enter markets. Although future predictions of micro-EV potential remain positive, there remains an inherent element of risk involved in their implementation. Our index therefore provides an interesting insight on where to enter the transport market in order to minimise the risk of failure: it estimates, for the most part, that both Shanghai and London are cities where the market success of this technology is perhaps already possible. This is seen with scores above the 0.5 mark for all three results for Shanghai and for two out of three results for London. The results of the index further suggest, in the context of our two case studies, that if a micro-EV company wants to have the highest likelihood of market success, it should perhaps look to expand first in Shanghai - as it received the higher score - and then in London. In essence, the higher a city's index score, the greater the estimated propensity for market success of micro-EVs, and thus the city should be prioritised over other locations. A possible interesting explanation can be found to account for these differences in city propensity by returning to the phenomena of 'path dependency' and 'lock-in' that were discussed in the background. Although the difficulties of succeeding in the face of these phenomena have been demonstrated, the Background section also highlighted how EVs and micro-mobility innovations have still managed to succeed in the market. The results returned by our index also indicate that, particularly in Shanghai, micro-EVs might be able to be successful. How and when do these successful cases occur?

Systems can experience moments where they are more "plastic", and hence more open to innovations that push towards less carbon-intensive pathways. This can occur in emerging sectors, such as is the case in many developing countries of the world, or at moments where lockedin sectors are disrupted by technological, economic, political or social changes that reduce the costs of the technology or the transition [45]. In developing countries, the technological, institutional and behavioural pathways of the transport sector are generally more flexible because the infrastructure required to effectively meet the needs of their growing economies and populations has not yet been solidified. Thus, there may exist opportunities for innovations to more rapidly change the trajectory of the transport sector before a high degree of lockin occurs (ibid). Jochem \& Madlener [26] also highlight 
the value of 'leapfrogging' for developing countries to avoid carbon-intensive technological lock-in, i.e., avoiding certain pattern characteristics and related technologies of developed countries. Instead, developing countries can directly implement technologies with lower carbon intensity, enabling these technologies to mature, reducing costs and building new norms of development. This leapfrogging is far more beneficial than in developed countries, where the benefits of such technologies become known, but policies then do not have sufficient power to push for their widespread adoption due to lock-in (ibid). Business and markets are primarily motivated by profit, but they also seek the stability that increases the predictability of financial returns on investments. They can therefore be convinced to support transitions if they understand how the pathway change will reduce risk and uncertainty, stabilise the economic market, improve economic efficiency or promote standardisation and industrial concentration (ibid). Clearly, people's choices matter; the products they consume and the energy and transport choices that they make will directly impact the degree of lock-in of the overall system. Crucially, this emphasizes three important points regarding lock-in and the results of our index. Firstly, a city's propensity for micro-EV market success is essentially a measure of the degree of lock-in of that city, as the CI measures variables related to both the consumer and the micro-EV manufacturer, but also the structural, economic and political environments of each city.

Secondly, developing countries and their cities are more likely to have relatively "plastic" systems, and thus to experience a smaller degree of lock-in and have a higher propensity for innovation market success [40]. The use of London and Shanghai as case studies for the index has highlighted this difference in transport system "plasticity" between the developing and developed world. London's transport system seems to be effectively experiencing a high degree of 'lock in' - the economic and regulatory stability has engrained ICEVs into the fabric of the society, making it difficult for new innovations to displace them. Undoubtedly, the high degree of lock-in is related to the long-term historical development of the city's road transport system. Conversely, China is still considered a developing country by the WTO [34]. Its development, particularly cities such as Shanghai, has occurred on a very short timescale, thus following a different path than Europe's long-term historical advancements. This has enabled Shanghai to leapfrog many developmental stages of the European transport system, and therefore has limited the amount of positive feedback loops of ICEVs.

Thirdly, lock-in can be surmounted by taking advantage of 'windows of opportunity' that sometimes appear within regimes via a conscious and collective effort of individuals, especially of consumers [45]. The necessity for a sustainable solution that solves increasingly dramatic transport pollution, health and efficiency problems is currently creating one such window (ibid). This can be achieved by augmenting the direct benefits to the consumer to incentivise micro-EV innovations as the present-day best possible solution. As Shanghai currently has higher scores in consumer-related subcategories, such as EV charging ports, it is more likely that endusers will make the conscious decision to purchase a micro-EV there than in London. It also implies that London's propensity for micro-EV uptake could be augmented if consumer benefits are increased, such as by lowering the Price of the technology.

Therefore, by highlighting the cities which have the highest potential for micro-EV market success, the index enables manufacturers to consider beginning the implementation of micro-EVs in regions potentially more receptive to the technology. This theoretically reduces the risk of innovation and company failure. Furthermore, this can have an additional effect of reducing costs of micro-EVs globally, increasing their attractiveness and their global market support. In the future, this could create new windows of opportunity for cities which currently experience more lock-in by motivating a broader societal movement in favour of micro-EVs, and ultimately in favour of the sustainability transition in the transport sector.

\section{Conclusions}

\subsection{Conclusion}

This paper has aimed to explore the propensity of market success of micro-EVs in cities. This technology lies at the intersection of two important trends: vehicle electrification and micro-mobility. As such, they provide an increasingly exciting opportunity to tackle many issues that ICEVs currently present. In order to minimise the risk of innovation failure and maximise the possibility for the successful market implementation of micro-EVs, a composite indicator (CI) was constructed that measures 16 variables related to market, economic, legal and organisational aspects of cities. This enabled us to effectively explore a city's overall propensity for micro-EV market success, taking into account the system's wider framework conditions. London and Shanghai were utilised as case study cities, because both cities are being considered by micro-EV companies for implementation of the technology, but there is little literature which assesses current implementation status.

Our research adopted three different weighting methodologies to maintain broadness of scope and objectivity, which consistently highlighted that Shanghai has a higher propensity for micro-EV market success than London. As the CI was a measurement of the overall 
propensity for market success of the existing system, cities which score lower are most likely locations which experience a greater degree of lock-in in their transport sector. This lock-in makes it difficult for new innovations to be successful as they compete with established technologies that are support by positive social, technological, economic and political feedback loops. Despite this, our results align with literature that states that there sometimes exist windows of opportunity that enables innovations to be successful in the market, particularly in developing countries where lock-in is generally less, but also via a conscious and collective effort of individuals who are incentivised to support the transition. These results suggest that micro-EV companies should look to first expand in Shanghai which may be experiencing less lock-in effect than London.

\subsection{Limitations}

The methodology utilised in this paper must be considered critically. Firstly, it should be highlighted that the use of this composite index (CI) is primarily to provide an exploratory tool for investors on micro-EV propensity for market success. In this way, the CI aims to primarily explore and inform companies and industries and as such, it has not been designed to be utilised as a policy tool or for sustainability assessments by cities nor by individuals.

In addition, the use of a $\mathrm{CI}$ has several drawbacks that must be taken into account. The OECD Handbook for Composite Indicators [37], expounds that CIs "may send misleading policy messages if poorly constructed or misinterpreted". It is hoped that this limitation is minimised by providing a transparent, clear and statistically sound methodology, and by clarifying that this tool is in no way intended for policy purposes.

Moreover, the data utilised in the creation of the index was carefully selected from reputable indices, government papers or expert sources in the transport, innovation and CI-creation fields. This maximised the reliability and robustness of the data, which was further tweaked and tested by modelling the index in the multimodel approach. Further works should continue to run sensitivity analyses via the multi-modal approach, as well as consider the use of other methodologies such as regressions analyses in $\mathrm{R}$.

Finally, where possible, the CI has sought to use citylevel data calibrated on a per capita basis in order to ensure that the country/city context remains coherent, and thus that the index can be extrapolated across global cities of varying sizes. Crucially, this data remains a snapshot at the moment the CI was created, and therefore it is recommended that the index be recalculated on a yearly basis in order to ensure that results remain reliable and informative.

\subsection{Further works}

The results presented by this study therefore provide insight on i) the potential of micro-EVs for the future, as well as ii) the need for research and quantitative tools to study more closely where these technologies should be pioneered to maximise the possibility of successful market uptake. The research also highlights a need for further studies which assess (a) which variables are the most relevant for studying sustainable urban mobility; (b) which variables are most important for innovation market success and (c) which statistical and weighting methodologies are most relevant for these themes. In addition, future works could seek to combine both primary and secondary data to increase the robustness of the data utilised in the study. Finally, further iterations and developments of the index's subcategories and the methods used for weighting could enable the index itself to become a potential commercial tool that provides businesses with key insights into which cities might have the highest propensity for micro-EV market success.

\section{Acknowledgements \\ The authors would like to thank Prof. Neil Strachan for supporting this work. \\ Authors' contributions \\ IL completed the literature review. MM suggested the methodology and IL completed the analysis. IL drafted the earlier versions of the manuscript and MM completed the final version of the manuscript. All authors read and approved the final manuscript.}

\section{Funding}

Funding information is not applicable.

Availability of data and materials

Data sharing is not applicable to this article as no datasets were generated.

\section{Competing interests}

The authors declare that they have no competing interests.

Received: 8 July 2019 Accepted: 19 March 2020

Published online: 09 June 2020

\section{References}

1. Alibaba, 2019. Chinese micro cars, Chinese Micro Cars Suppliers and Manufacturers at Alibaba.com. Available at: https://www.alibaba.com/ showroom/chinese-micro-cars.html. [Accessed 17 Apr 2019].

2. Allman, K. (2011). Measuring wider framework conditions for successful innovation: A systems review of UK and international innovation data. London: NESTA.

3. Anderson, C. D., \& Anderson, J. (2010). Electric and hybrid cars: A history. Jefferson: McFarland.

4. Boren, S., \& Ny, H. (2016). A strategic sustainability analysis of electric vehicles in EU today and towards 2050. International Journal of Environmental and Ecological Engineering, 10(3), 294-302.

5. Bree, B. V., Verbong, G., \& Kramer, G. (2010). A multi-level perspective on the introduction of hydrogen and battery-electric vehicles. Technological Forecasting and Social Change, 77(4), 529-540.

6. Brunner, H., et al. (2018). Evaluation of various means of transport for urban areas. Energy, Sustainability and Society, 8(1), 9.

7. Burton, N. (2013). A history of electric cars. Ramsbury: Crowood.

8. Charter, M., \& Clark, T. (2007). Sustainable innovation key conclusions from sustainable innovation conferences 2003-2006 organised by the Centre for Sustainable Design. Farnham: The Centre for Sustainable Design.

9. Chinese Academy of Engineering. (2003). Personal Cars and China Washington DC: The National Academies Press. 
10. Cohen, T. (2018). Being ready for the next Uber: Can local government reinvent itself? European Transport Research Review, 10(2), 57.

11. Danielis, R., Rotaris, L., \& Monte, A. (2017). Composite indicators of sustainable urban mobility: Estimating the rankings frequency distribution combining multiple methodologies. International Journal of Sustainable Transportation, 12(5), 380-395.

12. Department for Transport. (2019). Future of mobility: urban strategy. London: The Crown

13. Dora, C., \& Phillips, M. (2000). Transport, Environment and Health, WHO Regional Publications European Series (Vol. 89).

14. Drenth, M. (2018). New Energy Vehicles. Beijing: Embassy the Kingdom of the Netherlands.

15. Driscoll, P. A. (2014). Breaking carbon lock-in: Path dependencies in largescale transportation infrastructure projects. Planning Practice and Research, 29(3), 317-330.

16. Du, J., \& Ouyang, D. (2017). Progress of Chinese electric vehicles industrialization in 2015: A review. Applied Energy, 188, 529-546.

17. Dutta, S., Lanvin, B., \& Wunsch-Vincent, S. (2018). Global innovation index 2018: Energizing the world with innovation. Global Innovation Index, 11.

18. EEA. (2018). Electric vehicles from life cycle and circular economy perspectives. TERM 2018: Transport and environment reporting mechanism (TERM) report. Copenhagen: European Environment Agency.

19. Fokaides, P. A. (2019). Technological developments in land transportation in Cyprus in the early 20th century. Case Studies on Transport Policy, 7(2), 470476.

20. Geels, F. (2012). Automobility in transition?: A socio-technical analysis of sustainable transport. New York: Routledge.

21. Hall, D., Cui, H., \& Lutsey, N. (2018). Electric vehicle capitals: Accelerating the global transition to electric drive. Beijing: International Council of Clean Transportation.

22. Harrop, P. (2018). Micro EVs, e-Bikes, e Scooters, e Motorbikes, Mobility for Disabled 2018-2028. Cambridge: IDTechEx.

23. Helmers, E., \& Marx, P. (2012). Electric cars: technical characteristics and environmental impacts. Environmental Sciences Europe, 24(1).

24. Høyer, K. G. (2008). The history of alternative fuels in transportation: The case of electric and hybrid cars. Utilities Policy, 16(2), 63-71.

25. Jefferies, D. (2017). Smaller, lighter, greener: Are micro EVs the future of city transport? In The Guardian Available at: https:/www.theguardian.com/ sustainable-business/2017/may/11/micro-evs-city-transport-suemens-renaultgreen-air-pollution. [Accessed 17 Apr 2019].

26. Jochem, E., \& Madlener, R. (2003). The forgotten benefits of climate change mitigation: Innovation, technological leapfrogging, employment, and sustainable development. Paris: OECD.

27. Joumard, R., \& Gudmundsson, H. (2010). Indicators of environmental sustainability in transport: An interdiciplinary approach to methods. Lyon: INRETS.

28. Klitkou, A., et al. (2015). The role of lock-in mechanisms in transition processes: The case of energy for road transport. Environmental Innovation and Societal Transitions, 16, 22-37.

29. Luzzati, T., \& Gucciardi, G. (2015). A non-simplistic approach to composite indicators and rankings: An illustration by comparing the sustainability of the EU countries. Ecological Economics, 113, 25-38.

30. Mayor of London. (2015). London Infrastructure Plan 2050: Transport Supporting Paper. London: Mayor of London.

31. Mitchell, G., May, A., \& McDonald, A. (1995). Picabue: A methodologica framework for the development of indicators of sustainable development. International Journal of Sustainable Development and World Ecology, 2(2), 104-123.

32. MSU-CIBER. (2018). Market Potential Index. globalEDGE Available from: https://globaledge.msu.edu/global-resources/resource/1076. [Accessed 10 Dec 2018].

33. Nie, Y., et al. (2018). Examining Shanghai Consumer Preferences for Electric Vehicles and Their Attributes. Sustainability, 10(6), 2036.

34. Nogués, J. (2002). China and the WTO: A developing country perspective. In China in the WTO (pp. 143-164)

35. Nykvist, B., \& Whitmarsh, L. (2008). A multi-level analysis of sustainable mobility transitions: Niche development in the UK and Sweden. Technological Forecasting and Social Change, 75(9), 1373-1387.

36. Oberal, A. (1995). Innovation and commercialization of emerging technologies. Washington DC: U.S. Government Printing Office.
37. OECD. (2008). Handbook on constructing composite indicators: Methodology and user quide. Paris: OECD.

38. Ouboter, W., 2018. Microlino: This is not a car! micro-mobility.com. Available at: https://www.micro-mobility.com/en/experience-micro/microlino. [Accessed 17 Apr 2019].

39. Pedersen, N. (2015). The Socioeconomic Costs Related to Air Pollution in China. Beijing: The Royal Danish Embassy.

40. Perkins, R. (2003). Technological "lock-in". Internet Encyclopaedia of Ecological Economics.

41. PWC. (2013). Innovation: How to convert Research into commercial success story. Luxembourg: European Commission.

42. Riano, Q. (2008). Shanghai Mobility On Demand Urban Implementation Case Study. Massachusetts: Massachusetts Institute of Technology.

43. Roumboutsos, A., Kapros, S., \& Vanelslander, T. (2014). Green city logistics: Systems of Innovation to assess the potential of E-vehicles. Research in Transportation Business and Management, 11, 43-52.

44. Semenov, A. (2017). Why Will Micro Mobility Industry Make the Future? Splyt Medium Available at: https://medium.com/@Splyt/why-willmicro-mobilityindustry-make-the-future-1b0a628ae3d0. [Accessed 2 Apr 2019].

45. Seto, K. C., et al. (2016). Carbon lock-in: Types, causes, and policy implications. Annual Review of Environment and Resources, 41(1), 425-452.

46. Sworder, C., et al. (2017). The global Cleantech innovation index 2017. Berlin: WWF

47. Tett, M. (2017). A country in a jam: tackling congestion in our towns and cities How councils are dealing with congestion and how they could do more. London: Local Government Association.

48. Thornton, T., et al. (2018). Disruptive Innovation and Win-Win Strategies for the Sharing Mobility Economy. Oxford: Environmental Change Institute.

49. Transport for London. (2015). Crossrail 2: An essential piece of national infrastructure. London: Network Rail.

50. Witzel, S. (2018). In SkedGo (Ed.), How micro mobility solves multiple problems in congested cities Available at: https://skedgo.com/how-micro-mobilitysolves-multiple-problems-in-congested-cities/. [Accessed 15 Apr 2019].

51. Wood, L. (2018). Micro EVs, e-bikes, e-scooters, e-motorbikes, mobility for disabled 2018-2028. Dublin: Research and Markets.

52. Xue, L. (2014). A "new normal" for sustainable transport in Chinese cities. TheCityFix Available at: https://thecityfix.com/blog/new-normal-sustainabletransport-chinese-cities-transit-oriented-development-lulu-xue/. [Accessed 3 Mar 2019].

53. Zachariadis, T. (2006). On the baseline evolution of automobile fuel economy in Europe. Energy Policy, 34(14), 1773-1785.

54. Zion Market Research. (2018). Small electric vehicle market by vehicle type (2 or 3 wheeler, passenger cars, and light commercial vehicle), by technology (hybrid electric vehicle, plug-in hybrid electric vehicle, and battery electric vehicle), global industry perspective, comprehensive analysis, and forecast, 2017-2024. Zion Market Research.

\section{Publisher's Note}

Springer Nature remains neutral with regard to jurisdictional claims in published maps and institutional affiliations.

\section{Submit your manuscript to a SpringerOpen ${ }^{\circ}$ journal and benefit from:}

- Convenient online submission

- Rigorous peer review

- Open access: articles freely available online

High visibility within the field

- Retaining the copyright to your article

Submit your next manuscript at $>$ springeropen.com 